\title{
Network structure and spatial separation
}

\author{
Pavithra Parthasarathi \\ Hampton Roads Transportation Planning Organization (HRTPO), 723 Woodlake Drive, \\ Chesapeake, VA 23320, USA; e-mail: pparthasarathi@hrpdcva.gov
}

\section{Hartwig Hochmair}

Fort Lauderdale Research and Education Center (FLREC), University of Florida, 3205 College Avenue, Fort Lauderdale, FL 33314, USA; e-mail: hhhochmair@ufl.edu

\section{David Levinson}

Network, Economics, and Urban Systems Research Group, Department of Civil Engineering, University of Minnesota, 500 Pillsbury Drive SE, Minneapolis, MN 55455, USA;

e-mail: dlevinson@umn.edu

Received 2 November 2009; in revised form 12 January 2011

\begin{abstract}
This research aims to identify the role of network architecture in influencing individual travel behavior using travel survey data from Minneapolis-Saint Paul and Florida (Fort Lauderdale and Miami). Various measures of network structure, compiled from existing sources, are used to quantify roadway networks, and to capture the arrangement and connectivity of nodes and links in the networks and the spatial variations that exist among and within networks. The regression models show that travel behavior is correlated with network design.
\end{abstract}

Keywords: network structure, travel behavior

\section{Introduction}

Planners have traditionally shown keen interest in the use of land-use and urban design strategies not only to bring about changes in travel behavior but as a way of providing a better quality of life for residents. Traditional neighborhood designs are asserted to be better than postwar suburban developments in terms of land-use mix and greater accessibility to a variety of commercial establishments, grid-like arrangement of streets, traffic-calming strategies, and availability of sidewalks and other amenities suited to nonmotorized travel (Cervero and Gorham, 1995; Handy, 1992).

While the use of urban design and associated accessibility to influence travel makes intuitive sense, researchers have found it extremely difficult to provide clear evidence on the existence, much less the extent, of this complex relationship. Review of the literature in this area shows many differences in the modeling methodologies used (Crane, 2000; Krizek, 2003). Apart from the differences in modeling methodologies, the research community has also been divided on the actual impact of urban design on travel patterns. On the one extreme, there are researchers who argue for the existence of a significant relationship between urban form and travel (Cervero and Radisch, 1996; Frank and Pivo, 1994; Kockelman, 1997) and on the other extreme, there are researchers who counter that the impact of urban form on travel is weak at best (Boarnet and Crane, 2001; Crane, 2000). Researchers such as Kitamura et al (1997) and McNally and Kulkarni (1997) argue that attitudinal and socioeconomic factors are greater indicators of travel patterns than land-use variables and that land-use and urban design policies might not necessarily bring about measurable changes in travel behavior. 
While many modeling methodologies and approaches have been proposed by researchers to analyze the relationship between urban form and travel behavior, consideration of the structure of the actual transportation network has been largely missing. The transport system, specifically the street system, plays the role of the primary structural element of any city. For example, as Marshall (2005) points out, the differences between modern cities such as New York or Los Angeles trace back to the transportation system in place during critical phases of growth for each city. An in-depth analysis of urban design and travel must explicitly consider the transportation network in terms of the structure: the actual layout of streets.

The traditional interest in understanding transportation network structure has been limited to geographers who view the spatial nature of the transportation network as a vital input to regional development. Transportation planners acknowledge the importance of the transport system influencing urban form. However, most studies looking at the influence of urban form consider only a coarse representation of easily measured metrics of the actual transportation network such as the density of the road network, the number of three-way or four-way intersections, cul-de-sacs, or the length of street network (Cervero and Kockelman, 1997; Handy, 1992; Srinivasan, 2002). While these descriptive measures of roadway network structure are important in microneighborhood development, other measures of network structure may in addition affect driver behavior and the performance of the transportation system.

The question of how travel behavior varies systematically with network structure is particularly important as network architecture is perhaps the slowest changing urban system. For that reason it is the most important to get right, as design of the network persists for centuries and is difficult to adjust, much less optimize. In this paper we aim to expand understanding of the affect on travel behavior of underlying highway network structure, using data from Minneapolis-Saint Paul and Florida (Fort Lauderdale and Miami). The results from this analysis throw light on how a transportation network influences travel behavior.

The remainder of the paper is organized as follows: The next section briefly reviews relevant literature on network measures. This is followed by sections on the theory, modeling methodology, data sources, and estimation of measures of roadway network structure. The statistical analyses conducted and the results are presented in the next section. The paper concludes with key findings from the study and future extensions to the current research.

\section{Research synthesis}

Kissling (1969) refers to network structure as a measure of the layout of the network and characteristics of individual elements in his analysis of the influence of network structure on linkage importance and nodal accessibility levels in the Nova Scotia region. Xie and Levinson (2007) provide a similar definition of network topology as the arrangement and connectivity of the network. Geographers have traditionally been interested in understanding the structure of a transportation network as an aspect of the geographical area. A topological approach based on graph-theoretic network analysis has typically been employed by geographers to understand the spatial aspects of transportation along with the underlying processes that created them (Haggett and Chorley, 1969; Rodrigue et al, 2006; Taaffe et al, 1996).

One of the earliest analyses on utilizing network measures to understand metropolitan settlement patterns was conducted by Borchert (1961). In this study the numbers of road and street intersections per square mile in a $1300 \mathrm{mile}^{2}\left(3400 \mathrm{~km}^{2}\right)$ area representing Minneapolis-Saint Paul were used as quantitative measures to analyze settlement patterns. The results indicated a close relationship between the road intersection density 
and other indices of settlement patterns such as street mileage, parcel density, and residential density.

Kansky (1963) utilized graph theory and statistical methods to develop a wide range of network measures using mathematical logic and graph theory to quantify the spatial structure of transportation networks (railways and roadways) in his dissertation on the relationship between the structure of transportation networks and regional economic characteristics. The results confirmed the spatial and temporal association between the degree of transportation network structure and degree of regional economic development, after controlling for independent variables such as technological scale, size, shape, and relief.

Kansky's research was based on a study conducted by Garrison and Marble (1961) analyzing the relationship between the structure of transportation networks and characteristics of the area in which the networks are located. Recently Li and Shum (2001) developed accessibility measures based on graph theory to analyze the impacts of the National Trunk Highway System (NTHS) program in China. The highway system was abstracted as a 'valued graph' topologically and a nodal accessibility matrix based on the minimum distance was developed to quantify the accessibility at each nodal location and the change in accessibility over time, due to the construction of the NTHS system.

In a study evaluating pedestrian environments, Hess (1997) utilized quantitative measures of street network connectivity to explain the differences in pedestrian volumes between two neighborhoods (Wallingford and Crossroads) in the Seattle area. Dill (2004) presented results from an ongoing research project evaluating various measures of network connectivity for the purposes of increasing walking and biking.

In a study looking at the journey to work, Levinson and El-Geneidy (2009) used circuity as a tool to better understand the relationship between residential location choice relative to work, using data from the Twin Cities metropolitan region. Network circuity is defined as the ratio of the actual network distance to the Euclidean or straight-line distance between an origin and destination. Network circuity measured for a random selection of origins and destinations was compared with the circuity measured for actual origins and destinations. Workers tend to select commutes with lower circuity, applying their intelligence to locational decisions. The circuity measure has also been utilized at a national level using road networks from twenty-six countries (Ballou et al, 2002).

Jiang and Claramunt (2004) combined computational and experimental findings to conduct a topological analysis of large urban street networks. A functional graph approach was used, representing streets as vertices and nodes as edges, to estimate measures such as street connectivity, average path length, and clustering coefficients. Xie and Levinson (2007) investigated the potential application of proposed network measures in understanding and quantifying the structural attributes of complicated road networks. Three complementary measures of network structure-heterogeneity, connection patterns, and continuity - were developed and tested on idealized test networks. The proposed network measures were later applied to the Swiss road networks to trace the changes in network characteristics over time (Erath et al, 2009).

In a recent paper on network topology, Derrible and Kennedy (2009) study the relationship between graph-theory-based network measures (ie, transit coverage, directness, and connectivity) and transit ridership using data on nineteen subway systems worldwide. The results of the regression model show a strong relationship between the network measures and ridership, indicating the importance of network design in attracting people to transit systems. 


\section{Theory}

This research proposes that the key measurable characteristics of transportation network architecture affect travel behavior, such as trip length, after controlling for attributes that are not explicitly network based, such as land use, urban scale, and sociodemographic factors.

The relationship used in the analysis is given by:

$$
T=\mathrm{f}(N, L, S),
$$

where

$T$ is the travel behavioral decision

$N$ is the network structure,

$L$ is land use,

$S$ is a set of sociodemographic characteristics (eg, gender, age, household size, residence type).

Previous research has implicitly assumed that network structure could be reduced to network travel time or network distance. This research aims to unpack that assumption for several reasons.

First, while actual distance and time are likely to be important variables affecting the perception of travel distance and travel time, as much research has shown in the transit mode choice literature (van Exel and Rietveld, 2010) and in route choice (Levinson et al, 2004; 2006; Zhang et al, 2009; Zhu, 2010), not all travel time is weighted the same, much less perceived accurately (Parthasarathi et al, 2011a).

Second, if travel time or network or aerial distance is the independent variable, the use of travel time directly on the right-hand side of the equation begs the question of the affect of the network on that travel time.

Third, things which increase actual travel time, given a fixed origin and destination, decrease the willingness to choose that fixed origin and destination in the first place. Increasing a route's cost decreases demand for that route. Identifying the effects of network structure on actual travel behavior will produce different effects than identifying the effects of network structure on travel time.

Fourth, policy makers and development regulators can establish rules which affect the architecture of networks (Southworth and Ben-Joseph, 2003), but cannot easily establish rules which affect network travel time.

\section{Hypothesis}

The model identified above is operationalized with a set of specific hypotheses.

- The first broad hypothesis is that aspects of network structure which increase network travel distance between fixed origins and destinations (operational variables: network circuity, shapefactor, treeness) will reduce actual travel distance undertaken by travelers at those origins. Travelers will respond to higher pointto-point travel times by reducing trip length (changing the point of destination vis-à-vis the point of origin).

- Second, aspects of network structure which decrease network speed (operational variable: street density) also reduce actual trip length. Similarly, aspects of network structure that increase network speed (operational variable: proportion of limited access highways) will increase trip length.

- Third, aspects of network structure which increase perceived travel complexity or decrease network efficiency (operational variable: discontinuity) will decrease actual trip length. 


\section{Modeling methodology \\ Data}

The data for this current analysis come from Minneapolis-Saint Paul and Florida (Fort Lauderdale and Miami). The data compilation process for the dependent and independent variables is detailed below.

\section{Travel behavior}

The travel behavioral data for the two study areas come from the respective household travel surveys. The travel surveys typically contain a complete recording of all trips undertaken by the selected traveler on the travel day such as the trip origin and destination, the purpose of the trip, the arrival and departure time of each trip, and the travel model used.

The data for Florida (Fort Lauderdale and Miami) come from the 1999 Southeast Florida Travel Survey, maintained by the Florida Department of Transportation (http:// www.fsutmsonline.net/). The travel network provides information on the one-day travel patterns of randomly selected residents in southeast Florida, comprising the counties of Palm Beach, Miami-Dade, and Broward. The Southeast Florida travel survey consists of 33082 trips undertaken by 4603 households comprised of 8873 individuals. For the purpose of our analysis, trips originating and destined for Fort Lauderdale (Broward County) and Miami (Miami-Dade County) alone were extracted from the complete travel survey dataset, which provided 9402 trips for the Fort Lauderdale area and 9334 trips for the Miami area. The 9402 trips in the Fort Lauderdale area comprise 1900 commute trips (home to work/work to home) while the 9334 trips in the Miami area comprise 2279 commute trips.

The data for Minneapolis-Saint Paul are from the Travel Behavior Inventory (TBI), a similar comprehensive one-day travel survey conducted by the Metropolitan Council and the Minnesota Department of Transportation. The TBI consists of 58345 trips undertaken by 6219 households comprised of 14671 individuals. The data were extracted to include only those trips that originated and were destined for the Twin Cities metropolitan area. The Twin Cities metropolitan area is defined here as the seven counties of Anoka, Carver, Dakota, Hennepin, Ramsey, Scott, and Washington. The extracted dataset consists of 38432 trips within the Twin Cities metropolitan area, of which there are 5341 commute trips.

Typical variables obtained from the travel surveys for analysis purposes include travel distance, trip mode choice, and socioeconomic variables.

\section{Street network}

The street network data for the study area (Twin Cities, South Florida) were extracted from 2000 Census TIGER/Line files (http://www.census.gov/geo/www/tiger). The extracted networks were cleaned and stratified into three main categories - arterials, interstates, and local streets-based on the Feature Class Codes (FCC) for the roadway segments provided in the Census TIGER/Line files. Figure 1 and 2 show the arterial and interstate networks of the study areas.

The free-flow speeds of the road segments provided in the street network were updated with actual speeds to better account for congestion. The average congested speeds in the Twin Cities network were obtained from an independent study (Zhu et al, 2010), conducted at the University of Minnesota. GPS units installed in subject vehicles were used as probes to accurately measure the travel speeds on the Twin Cities roadway segments. The actual speed data for Florida come from the Navteq Traffic Patterns speed data (http://www.navmart.com/navteq_traffic_patterns.php), which provide 15-minute raster traffic flow times derived from GPS observations of service subscribers. 
The travel survey data provide information on the origin and destination of each trip. The fastest path (computed over roadway segments weighted with average congested speeds) between the given trip origin and destination was identified for each trip in the survey dataset. A $1 \mathrm{~km}$ buffer was created around this path and various

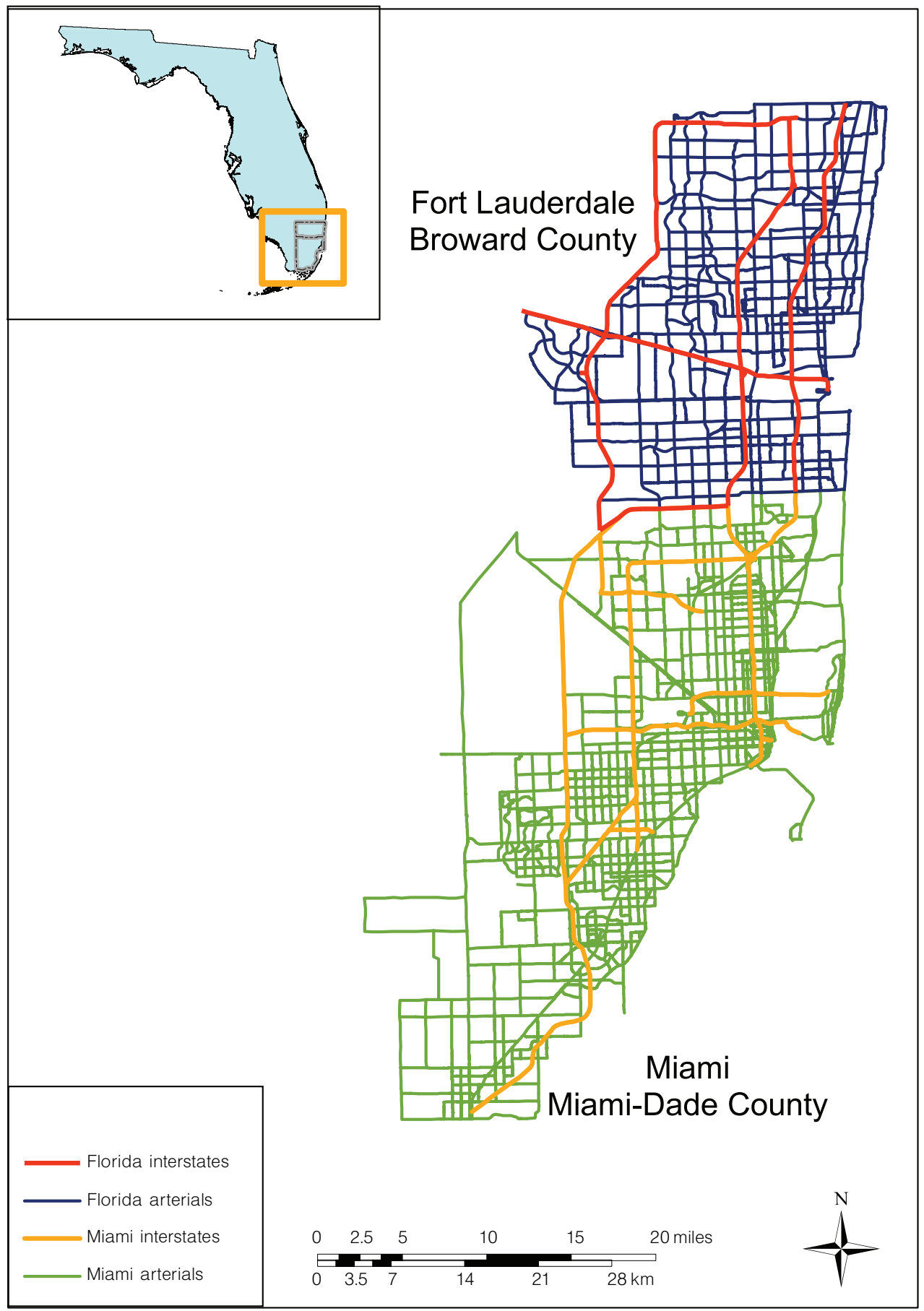

Figure 1. [In color online.] Fort Lauderdale and Miami study area. 
measures of network structure within the $1 \mathrm{~km}$ fastest path buffer were then estimated using the complete street network (including interstates, arterials, and local streets). A similar analysis was carried out using a subset network consistent of just the interstates and arterials in the two study areas. A $2 \mathrm{~km}$ buffer around the fastest path was used in the arterial network to estimate measures of network structure. This network differentiation better captures the variations in network structure at different roadway hierarchies.

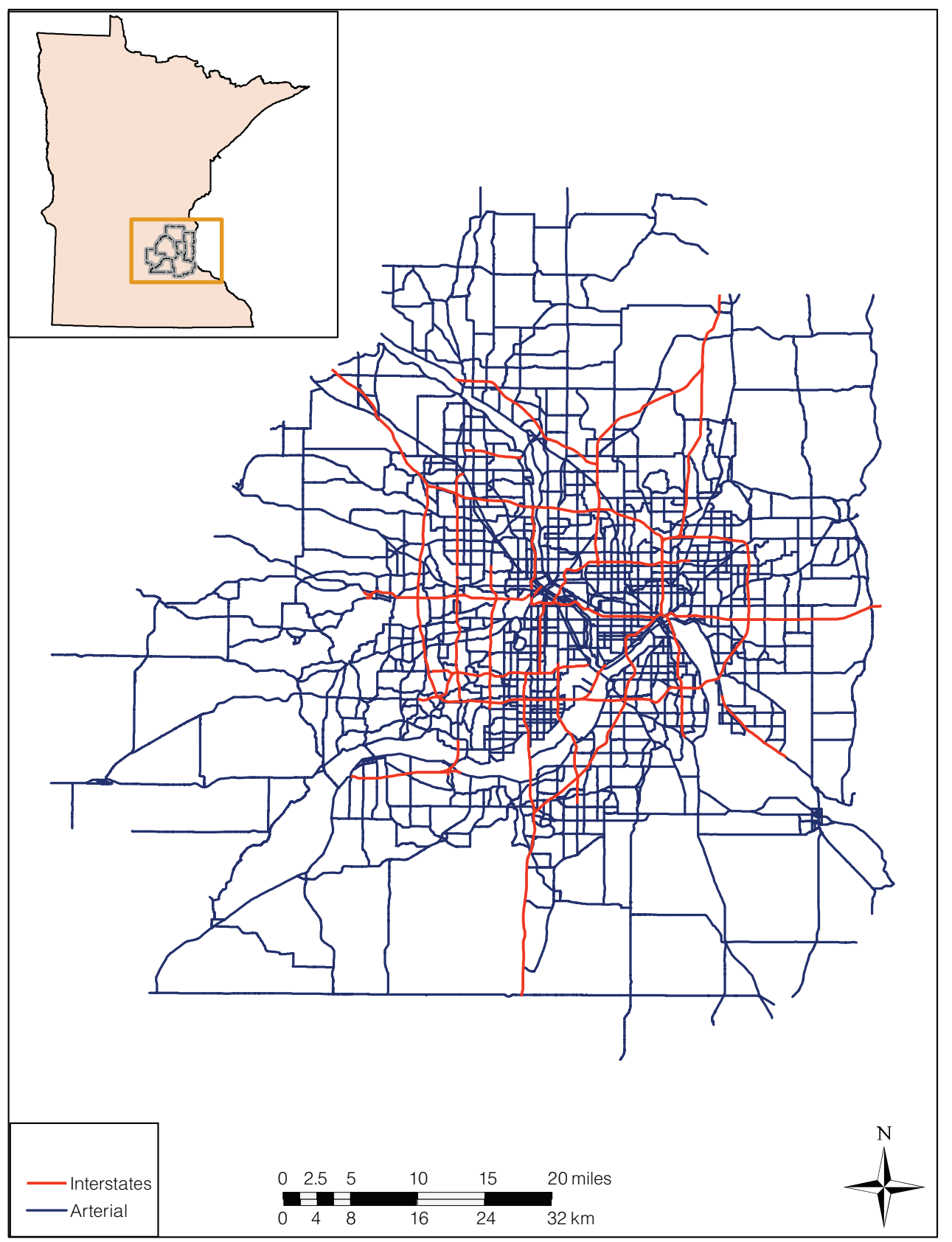

Figure 2. [In color online.] Twin Cities study area. 
Although travelers will not always follow the fastest route, it is a common route choice criterion for car drivers. The use of the fastest route or shortest travel time route from origin to destination is based on existing research on route choice. As Zhu et al (2009) point out, the trip-based modeling paradigm is based on Wardrop's first principle, in which "the journey times in all routes actually used are equal to less than those which would be experienced by a single vehicle on any unused route" (Wardrop, 1952, page 345). This assumption has been countered by researchers on route choice who argue that travel time is not the only criterion that travellers use. Our travel survey data contain information only on the trip origin and destination and no information on the actual routes. Considering the data that we have, we felt that the shortest travel time path is the best assumption that we can use.

Even if the route geometry deviates from the actually chosen route of a survey respondent, we do not expect that the network characteristic in the buffers around these two route alternatives will vary significantly or have a noticeable impact on the role of the network characteristics.

\section{Estimation of network measures}

The variables characterizing the network structure can be broadly categorized into four main categories: hierarchy, topology, morphology, and scale. The estimated measures of network structure used are described below. Some of the estimated measures have already been elaborated in related papers (Parthasarathi and Levinson, 2011; Parthasarathi et al, 2011b).

\section{Hierarchy measures}

The following attributes measure network heterogeneity.

Discontinuity and relative discontinuity

The discontinuity measure quantifies the number of changes in street hierarchy experienced along the fastest path between the trip origin and destination. The relative discontinuity measure is continuity divided by the trip length. As illustrated by Xie and Levinson (2007), consider a traveler moving from an upstream link with hierarchy $k_{1}$ to a downstream link with hierarchy $k_{2}$. The discontinuity is measured as:

$$
y_{a}=\left|k_{1}-k_{2}\right| \text {. }
$$

The discontinuity of the trip along the shortest past, $P$, is then estimated as:

$$
Y(P)=\sum_{a \in P} y_{a}
$$

The relative discontinuity is then estimated as:

$$
Y^{\prime}(P)=\frac{Y(P)}{l(P)},
$$

where

$Y(P)$ is the discontinuity of the trip along the shortest path,

$l(P)$ is the length $(\mathrm{km})$ of trip along the shortest path.

Proportion of limited-access roads

This measure captures the presence of higher hierarchy links such as interstate highways within each trip buffer. This measure is estimated as:

$$
\text { proportion of limited-access roads }=\frac{l_{\mathrm{lb}}}{l_{\mathrm{sb}}},
$$


where

$l_{\mathrm{lb}}$ is the total length $(\mathrm{km})$ of the limited-access roads within the trip buffer,

$l_{\mathrm{sb}}$ is the total length $(\mathrm{km})$ of the street network within the trip buffer.

The limited-access roadways in the street network were identified on the basis of FCC codes provided in the Census TIGER/line files. These roads are designed for higher speeds and hence facilitate longer travel.

\section{Topology measures}

These measures are typically based on elementary concepts of graph theory and provide a sense of connectivity and connection patterns in a network.

Arterial treeness

This unitless measure is based on the two basic structures of a planar transportation network: circuit and tree (Haggett and Chorley, 1969). A circuit is defined as a closed path, with no fewer than three links, that begins and ends at the same node. A regional network distinguished by closed circuits is called a circuit network. A tree is defined as a set of connected lines that do not form a complete circuit and a branching network is defined by a tree-shaped structure. Refer to Xie and Levinson (2007) and Parthasarathi et al (2011b) for a complete description of this measure.

$$
\phi_{\text {tree }}=\frac{l_{\mathrm{tb}}}{l_{\mathrm{ab}}},
$$

where

$l_{\mathrm{tb}}$ is the length $(\mathrm{km})$ of street segments belonging to a branch network within the buffer,

$l_{\mathrm{ab}}$ is the total length $(\mathrm{km})$ of the street network within the buffer.

The treeness measure is designed to capture the differences in topology and connection patterns that exist in a real-world street network. For the purposes of our analysis, the treeness was estimated for a subnetwork consisting only of arterials and interstates in both study areas.

Circuity

This measure is estimated between a given trip origin and destination as:

$$
C_{\mathrm{t}}=\frac{D_{\mathrm{n}}}{D_{\mathrm{e}}}
$$

where

$C_{\mathrm{t}}$ is the circuity of the trip between the origin and destination,

$D_{\mathrm{n}}$ is the network distance $(\mathrm{km})$ between the trip origin and destination,

$D_{\mathrm{e}}$ is the Euclidean distance $(\mathrm{km})$ between the trip origin and destination.

The network distance is a realistic representation of the actual transportation network distance along the fastest path between the origin and destination in this analysis. The Euclidean distance measures the straight-line distance between the origin and destination using the location coordinates (Levinson and El-Geneidy, 2009). The circuity measure is unitless.

\section{Morphological measures}

These measures describe the regularity of street networks, their shape, and fragmentation. Shapefactor

This measure captures the generated impedance of the street network. The estimation of this measure involves identifying all polygons enclosed by the street network. For each of these identified polygons, the shapefactor is estimated as:

$$
\text { shapefactor }=\frac{P_{\mathrm{p}}^{2}}{A_{p}},
$$


where

$P_{\mathrm{p}}$ is the perimeter $(\mathrm{km})$ of the polygon enclosed by the street network, $A_{\mathrm{p}}$ is the area $\left(\mathrm{km}^{2}\right)$ of the polygon enclosed by the street network.

In general, a higher value of this measure indicates greater impedance in circumnavigating the network. In our current analysis, the shapefactor of all the polygons that intersect the trip buffer is averaged to get the trip level shapefactor. The shapefactor is estimated for the complete street network. Parthasarathi et al (2011b) contains a detailed explanation of the shapefactor measure.

\section{Scale}

Street density

This measure is estimated for the complete street network as:

$$
\text { street density }=\frac{l_{\mathrm{sb}}}{A_{\mathrm{b}}},
$$

where

$l_{\mathrm{sb}}$ is the total length $(\mathrm{km})$ of the street network within the trip buffer,

$A_{\mathrm{b}}$ is the area $\left(\mathrm{km}^{2}\right)$ of the trip buffer.

Other measures of network structure, such as intersection density, percentage of nodal degree, and nodal entropy were also estimated. These measures are not elaborated here due to the high correlation between certain network variables. For example, preliminary analysis from the two study areas indicated a high degree of correlation between the shapefactor measure and the percentage of nodal degrees. The correlation between the various network measures is estimated to ensure that the variables capture different aspects of the network and is summarised in table 1 and 2 .

Some of the above network measures (for example, street density) are estimated based upon the entire buffer area. It could be argued that these measures should be estimated along the chosen route, rather than in relation to the buffer area. While we agree with the argument, we do not currently have information on the actual route between the trip origin and destination. Given the uncertainty about the actual route chosen, we believe the estimation of network measures based on the buffer to be a reasonable definition. If we have to have data on actual routes, we agree that the data on the exact route, not the buffer, should be used.

Table 1. Correlation of network measures-Twin Cities.

\begin{tabular}{|c|c|c|c|c|c|c|}
\hline & $\begin{array}{l}\text { Relative } \\
\text { discontinuity }\end{array}$ & Shapefactor & $\begin{array}{l}\text { Street } \\
\text { density }\end{array}$ & $\begin{array}{l}\text { Proportion } \\
\text { of limited- } \\
\text { access } \\
\text { highways }\end{array}$ & $\begin{array}{l}\text { Arterial } \\
\text { treeness }\end{array}$ & $\begin{array}{l}\text { Trip } \\
\text { circuity }\end{array}$ \\
\hline Relative discontinuity & 1.000 & & & & & \\
\hline Shapefactor & -0.045 & 1.000 & & & & \\
\hline Street density & 0.097 & -0.417 & 1.000 & & & \\
\hline $\begin{array}{l}\text { Proportion of limited- } \\
\text { access highways }\end{array}$ & -0.005 & 0.239 & 0.073 & 1.000 & & \\
\hline Arterial treeness & 0.017 & -0.173 & $-\mathbf{0 . 0 7 7}$ & 0.010 & 1.000 & \\
\hline Trip circuity & 0.036 & 0.048 & -0.019 & 0.022 & 0.002 & 1.000 \\
\hline
\end{tabular}


Table 2. Correlation of network measures-Florida.

\begin{tabular}{|c|c|c|c|c|c|c|}
\hline & $\begin{array}{l}\text { Relative } \\
\text { discontinuity }\end{array}$ & Shapefactor & $\begin{array}{l}\text { Street } \\
\text { density }\end{array}$ & $\begin{array}{l}\text { Proportion } \\
\text { of limited- } \\
\text { access } \\
\text { highways }\end{array}$ & $\begin{array}{l}\text { Arterial } \\
\text { treeness }\end{array}$ & $\begin{array}{l}\text { Trip } \\
\text { circuity }\end{array}$ \\
\hline Relative discontinuity & 1.000 & & & & & \\
\hline Shapefactor & -0.016 & 1.000 & & & & \\
\hline Street density & 0.104 & -0.406 & 1.000 & & & \\
\hline $\begin{array}{l}\text { Proportion of limited- } \\
\text { access highways }\end{array}$ & -0.119 & 0.059 & $-\mathbf{0 . 0 3 2}$ & 1.000 & & \\
\hline Arterial treeness & -0.008 & -0.220 & 0.162 & 0.057 & 1.000 & \\
\hline Trip circuity & 0.165 & 0.101 & -0.053 & 0.065 & -0.025 & 1.000 \\
\hline
\end{tabular}

\section{Control variables}

Distance measure

A distance measure was introduced to account for the accessibility and relative location of households with respect to the downtown or city center in both study areas. The downtown district in each study area was identified using Google maps (http:// maps.google.com/) and a working knowledge of the area. The transportation analysis zones (TAZ) corresponding to the downtowns in both study areas were identified using a GIS.

The Euclidean or straight-line distance from the household location to the respective downtowns was then estimated using the $X, Y$ coordinates of the household and the $X, Y$ coordinates of the TAZ centroid. The following were obtained:

- Twin Cities

distance to downtown Minneapolis, distance to downtown Saint Paul;

\section{- Florida}

distance to downtown Fort Lauderdale, distance to downtown Miami.

Sociodemographic variables

Sociodemographic variables were obtained from the travel survey data for the respective study areas and are used as control variables in our analyses. Typical variables include age, gender, employment type, income level, household size, and auto ownership.

\section{Analysis}

Two types of analyses are conducted here using the network and travel data for the two study areas. The first analysis uses the trip distance between the origin and destination, measured along the network, as the dependent variable. This analysis is further separated by trip purpose into analysis of work and nonwork trips. The second analysis uses the estimated vehicle kilometers traveled (VKT) per individual commuter as the dependent variable. The analysis is limited to auto-based (drive-along, carpool) trips in both study areas. The objective in these analyses is to understand the influence of network measures on the dependent variable, after accounting for nonnetwork control variables.

As mentioned previously, the first step in the analysis is to identify the fastest route between each reported origin-destination pair in the travel survey and estimate the network measures within each individual fastest-path buffer. Actual congested speeds on the road segments were used to identify the fastest path between the trip origin 
and destination. All measures of network structure, with the exception of arterial treeness, are estimated for the complete street network. The complete street network consists of the interstates, arterial, and local streets in the urban area while the arterial network is a subset of the complete network and consists of just the interstates and arterials. The buffer size around the fastest path varies by the network with a $1 \mathrm{~km}$ buffer used for the complete network and a $2 \mathrm{~km}$ buffer used for the arterial network. The buffer size, while admittedly arbitrary, provides us with a geographical definition that is required for the estimation of areal network measures.

A summary statistics of the estimated network measures for the two study areas is provided in table 3 .

Table 3. Summary statistics of network measures.

\begin{tabular}{|c|c|c|c|c|c|c|c|c|}
\hline \multirow{2}{*}{$\begin{array}{l}\text { Independent variables } \\
\text { (unit) }\end{array}$} & \multicolumn{4}{|c|}{ Twin Cities } & \multicolumn{4}{|l|}{ Florida } \\
\hline & mean & SD & $\min$ & $\max$ & mean & SD & $\min$ & $\max$ \\
\hline $\begin{array}{l}\text { Relative discontinuity } \\
\qquad(1 / \mathrm{km})\end{array}$ & 0.441 & 1.137 & 0.000 & 58.395 & 0.454 & 0.810 & 0.000 & 30.923 \\
\hline Shapefactor & 24.523 & 3.363 & 17.196 & 56.505 & 24.389 & 3.179 & 17.771 & 37.782 \\
\hline Street density $(1 / \mathrm{km})$ & 18.439 & 5.281 & 2.671 & 34.465 & 13.999 & 2.128 & 5.773 & 23.001 \\
\hline $\begin{array}{l}\text { Proportion of limited- } \\
\text { access highways }\end{array}$ & 0.049 & 0.045 & 0.000 & 0.268 & 0.062 & 0.058 & 0.000 & 0.456 \\
\hline Arterial treeness & 0.009 & 0.029 & 0.000 & 0.625 & 0.004 & 0.012 & 0.000 & 0.167 \\
\hline Trip circuity & 1.426 & 1.905 & 0.000 & 161.826 & 1.402 & 0.771 & 0.050 & 33.436 \\
\hline $\begin{array}{l}\text { Distance to downtown } \\
\text { Minneapolis }(\mathrm{km})\end{array}$ & 16.287 & 9.732 & 0.050 & 63.783 & & & & \\
\hline $\begin{array}{l}\text { Distance to downtown } \\
\text { Saint Paul }(\mathrm{km})\end{array}$ & 21.177 & 10.713 & 0.042 & 74.268 & & & & \\
\hline $\begin{array}{l}\text { Distance to downtown } \\
\text { Fort Lauderdale }(\mathrm{km})\end{array}$ & & & & & 28.114 & 18.913 & 0.472 & 81.815 \\
\hline $\begin{array}{l}\text { Distance to downtown } \\
\text { Miami }(\mathrm{km})\end{array}$ & & & & & 30.556 & 14.976 & 0.965 & 61.293 \\
\hline Number of observations & 19379 & & & & 4720 & & & \\
\hline
\end{tabular}

\section{Predicting trip (network) distance}

To obtain the dependent variable for the first analysis, the length of the street segments along the identified fastest path between each origin-destination pair is summed up to obtain the trip (network) distance. Separate regression models are estimated for the two study areas: Twin Cities and Florida (Fort Lauderdale and Miami). The two regression models of trip distance are:

(1) regression of trip distance of work trips,

(2) regression of trip distance of nonwork trips.

The stratification by trip purpose (work/nonwork) across the two study areas allows us to capture any variations in the influence of the independent network measures. Table 4 presents the results of the regression models of trip distance for work trips, while table 5 presents the results for nonwork trips, for both study areas. The sociodemographic variables are used as control variables in this analysis and are hence not elaborated here for brevity.

Looking at the results of the regression model trip distance for work trips, it is clear that most measures of network structure are significant and influence trip (network) distance as hypothesized, even after controlling for other independent variables. The measures of relative discontinuity, shapefactor, and street density have the expected negative influence on trip distance in both study areas. The proportion of 
Table 4. Predicting work trip (network) distance $(\mathrm{km})$ : origin to destination.

\begin{tabular}{|c|c|c|c|c|c|}
\hline \multirow[t]{2}{*}{ Independent variables } & \multirow[t]{2}{*}{ Hypothesis } & \multicolumn{2}{|l|}{ Twin Cities } & \multicolumn{2}{|l|}{ Florida } \\
\hline & & coeff. & $t$ & coeff. & $t$ \\
\hline $\begin{array}{l}\text { Distance to downtown } \\
\text { Minneapolis }\end{array}$ & & $0.22 * * *$ & 7.42 & & \\
\hline $\begin{array}{l}\text { Distance to downtown } \\
\text { Saint Paul }\end{array}$ & & $0.10 * * *$ & 4.10 & & \\
\hline $\begin{array}{l}\text { Distance to downtown } \\
\text { Fort Lauderdale }\end{array}$ & & & & $0.19 * * *$ & 7.18 \\
\hline $\begin{array}{l}\text { Distance to downtown } \\
\text { Miami }\end{array}$ & & & & $0.15 * * *$ & 5.31 \\
\hline Relative discontinuity & - & $-8.80 * * *$ & -2.73 & $-7.25 * * *$ & -7.88 \\
\hline Shapefactor & - & $-0.46^{* * *}$ & -6.01 & $-0.63 * * *$ & -6.81 \\
\hline Street density & - & $-0.41 * * *$ & -5.91 & $-0.55^{* * *}$ & -4.42 \\
\hline $\begin{array}{l}\text { Proportion of limited- } \\
\text { access highways }\end{array}$ & + & $94.41 * * *$ & 18.52 & $80.77 * * *$ & 20.18 \\
\hline Arterial treeness & - & $-35.90 * * *$ & -3.85 & -8.06 & -0.38 \\
\hline Trip circuity & - & $-1.98 * * *$ & -4.47 & -0.24 & -0.14 \\
\hline $\begin{array}{l}\text { Urban area dummy- } \\
\text { Miami }\end{array}$ & & & & -1.55 & -1.23 \\
\hline Constant & & $32.13 * * *$ & 11.17 & $24.76^{* * *}$ & 6.19 \\
\hline Number of observations & & 4105 & & 1492 & \\
\hline & & 0.301 & & 0.429 & \\
\hline Adjusted $R^{2}$ & & 0.298 & & 0.423 & \\
\hline
\end{tabular}

$* * * p<0.01$.

Table 5. Predicting nonwork trip (network) distance $(\mathrm{km})$ : origin to destination.

\begin{tabular}{|c|c|c|c|c|c|}
\hline \multirow[t]{2}{*}{ Independent variables } & \multirow[t]{2}{*}{ Hypothesis } & \multicolumn{2}{|l|}{ Twin Cities } & \multicolumn{2}{|l|}{ Florida } \\
\hline & & coeff. & $t$ & coeff. & $t$ \\
\hline \multicolumn{2}{|l|}{$\begin{array}{l}\text { Distance to downtown } \\
\text { Minneapolis }\end{array}$} & $0.03 *$ & 1.74 & & \\
\hline \multicolumn{2}{|l|}{$\begin{array}{l}\text { Distance to downtown } \\
\text { Saint Paul }\end{array}$} & $0.03 * * *$ & 2.72 & & \\
\hline \multicolumn{2}{|l|}{ Distance to downtown } & & & $0.07 * * *$ & 4.35 \\
\hline \multicolumn{2}{|l|}{$\begin{array}{l}\text { Distance to downtown } \\
\text { Miami }\end{array}$} & & & $0.11 * * *$ & 6.52 \\
\hline Relative discontinuity & - & $-1.22 * * *$ & -4.25 & $-2.10^{* * *}$ & -3.19 \\
\hline Shapefactor & - & $-0.45^{* * *}$ & -18.91 & $-0.42 * * *$ & -9.09 \\
\hline Street density & - & $-0.52 * * *$ & -20.46 & $-0.40^{* * *}$ & -5.66 \\
\hline $\begin{array}{l}\text { Proportion of limited- } \\
\text { access highways }\end{array}$ & + & $63.24 * * *$ & 28.60 & $64.38 * * *$ & 19.64 \\
\hline Arterial treeness & - & $-11.69 * * *$ & -5.12 & 11.99 & 0.74 \\
\hline Trip circuity & - & $-0.14 * *$ & -2.57 & $-0.70^{* * *}$ & -3.29 \\
\hline \multicolumn{2}{|l|}{$\begin{array}{l}\text { Urban area dummy- } \\
\text { Miami }\end{array}$} & & & 0.71 & 0.98 \\
\hline \multicolumn{2}{|l|}{ Constant } & $28.06 * * *$ & 26.34 & $19.88 * * *$ & 11.12 \\
\hline \multicolumn{2}{|l|}{$\begin{array}{l}\text { Number of observations } \\
R^{2} \\
\text { Adjusted } R^{2}\end{array}$} & $\begin{array}{l}15274 \\
0.157 \\
0.156\end{array}$ & & $\begin{array}{l}3228 \\
0.286 \\
0.282\end{array}$ & \\
\hline \multicolumn{4}{|c|}{$* p<0.10, * * p<0.05, * * * p<0.01$} & & \\
\hline
\end{tabular}


limited-access highways has a significant positive influence in both study areas, corroborating our hypothesis. The measures of arterial treeness and trip circuity have the expected negative coefficient in both areas. However, both measures are significant in the Twin Cities area alone. The distance measures, accounting for the relative location of the individuals' residence with respect to the downtown or city center, are positive and significant in both study areas. This is expected since individuals who live further away from the downtown or city center typically have lower accessibility and hence need to travel longer to access opportunities. The results of the regression model of trip distance for nonwork trips show similar patterns of influence but minor differences in the magnitude of influence of the independent variables, in both study areas.

The regression models for work trips and nonwork trips were tested for varying trip lengths: for example, trip lengths less than $20 \mathrm{~km}$, trip lengths between $20 \mathrm{~km}$ and $60 \mathrm{~km}$, and trip lengths greater than $60 \mathrm{~km}$. Such a stratification by trip distance allows us to check our hypotheses and see if the influence of the independent network measures varies with distance. The results, not presented here, show the same patterns of influence of network variables on trip distance in all the models. The next analysis presented below looks at how network measures along a recurring trip (eg, morning commute) affect the total travel undertaken by an individual in an urban area.

\section{Predicting vehicle kilometers traveled (VKT)}

The second analysis conducted in this paper regresses VKT per individual commuter on measures of network structure estimated along the home-to-work trip. The travel survey data are used to identify the commuters in the two study areas along with the trips undertaken by each commuter on the given travel day. The dependent variableVKT per individual commuter-is obtained by summing up the trip (network) distance between the origin and destination for all the identified trips. The VKT per individual commuter is then estimated as a function of the network measures along the home-to-work trip using a simple linear regression model (with robust standard errors).

There are two reasons for using the network measures along the home-to-work trip to predict VKT. Firstly, the home-to-work trip is a recurring trip and definitely contributes to an individual's total travel on a typical day. Secondly, preliminary analysis of the travel survey data (not presented here), confirms that the home-to-work trip distance constitutes a high percentage of the total daily VKT. For example, in the Twin Cities, for over $55 \%$ of the commuters, the home-to-work trip constitutes more than $50 \%$ of the total daily VKT.

The regression is conducted for both study areas and the results are tabulated in table 6. The socioeconomic variables are used as control variables in this analysis and are similarly not presented here for brevity. The results indicate that, while the influence of network structure on VKT per individual commuter is not as pronounced as the results for travel distance, there is influence of network structure measures on total travel.

The relative discontinuity is negative and significant in both study areas, confirming our hypothesis. Similarly, the proportion of limited-access highways is positive and significant in both study areas, in line with our hypothesis. The differences in the patterns of influence of the network measures between the two study areas arise in the following variables: the treeness variable is negative as hypothesized but is significant only in the Twin Cities area. The difference could be attributed to the higher number of roadway segments characterized as belonging to a tree network in the Twin Cities area compared with the Florida area. The trip circuity also shows a negative influence in both study areas but is also significant only in the Twin Cities. On the other 
Table 6. Predicting vehicle kilometers traveled per individual commuter.

\begin{tabular}{|c|c|c|c|c|c|}
\hline \multirow[t]{2}{*}{ Independent variables } & \multirow[t]{2}{*}{ Hypothesis } & \multicolumn{2}{|l|}{ Twin Cities } & \multicolumn{2}{|l|}{ Florida } \\
\hline & & coeff. & $t$ & coeff. & $t$ \\
\hline $\begin{array}{l}\text { Distance to downtown } \\
\text { Minneapolis }\end{array}$ & & $1.08 * * *$ & 8.77 & & \\
\hline $\begin{array}{l}\text { Distance to downtown } \\
\text { Saint Paul }\end{array}$ & & 0.13 & 1.47 & & \\
\hline $\begin{array}{l}\text { Distance to downtown } \\
\text { Fort Lauderdale }\end{array}$ & & & & $0.34 * * *$ & 3.24 \\
\hline $\begin{array}{l}\text { Distance to downtown } \\
\text { Miami }\end{array}$ & & & & $0.29 * * *$ & 2.87 \\
\hline Relative discontinuity & - & $-13.22^{* *}$ & -2.31 & $-9.41 * * *$ & -3.68 \\
\hline Shapefactor & - & -0.06 & -0.22 & $-0.67^{*}$ & -1.74 \\
\hline Street density & - & 0.36 & 1.56 & $-1.75^{* * *}$ & -3.55 \\
\hline $\begin{array}{l}\text { Proportion of limited- } \\
\text { access highways }\end{array}$ & + & $182.88^{* * *}$ & 10.52 & $131.51 * * *$ & 8.81 \\
\hline Arterial treeness & - & $-104.96^{* * *}$ & -4.34 & -8.52 & -0.13 \\
\hline Trip circuity & - & $-4.01 * * *$ & -4.47 & -2.63 & -0.88 \\
\hline $\begin{array}{l}\text { Urban area dummy- } \\
\text { Miami }\end{array}$ & & & & -0.38 & -0.08 \\
\hline Constant & & $20.67^{*}$ & 1.88 & $52.71 * * *$ & 3.47 \\
\hline $\begin{array}{l}\text { Number of observations } \\
R^{2} \\
\text { Adjusted } R^{2}\end{array}$ & & $\begin{array}{l}2296 \\
0.200 \\
0.195\end{array}$ & & $\begin{array}{l}1112 \\
0.161 \\
0.148\end{array}$ & \\
\hline$* p<0.10, * * p<0.05, *$ & $<0.01$ & & & & \\
\hline
\end{tabular}

hand, the shapefactor and street density variables corroborate the hypothesis of negative influence in the Florida area, but show no significant influence in the Twin Cities.

The distance measures to the downtowns in both study areas are also positive and significant, similar to the above models of trip distance. This suggests that individuals who reside farther away from the city center typically have more daily travel, in line with existing literature on travel behavior. In summary, the regression models corroborate the formulated hypotheses and show the same patterns of influence except for some minor differences between the two study areas. A summary of the formulated hypotheses and the results of the analysis are provided in table 7.

Table 7. Summary of regression results (S significant, NS not significant).

\begin{tabular}{|c|c|c|c|c|c|c|c|}
\hline \multirow[t]{3}{*}{$\begin{array}{l}\text { Independent network } \\
\text { variables }\end{array}$} & \multirow[t]{3}{*}{ Hypothesis } & \multicolumn{4}{|c|}{$\begin{array}{l}\text { Trip distance between origin } \\
\text { and destination }\end{array}$} & \multirow{2}{*}{\multicolumn{2}{|c|}{$\begin{array}{l}\text { Vehicle kilometers } \\
\text { traveled per indivi- } \\
\text { dual commuter }\end{array}$}} \\
\hline & & \multicolumn{2}{|c|}{ work trips } & \multicolumn{2}{|c|}{ nonwork trips } & & \\
\hline & & $\begin{array}{l}\text { Twin } \\
\text { Cities }\end{array}$ & Florida & $\begin{array}{l}\text { Twin } \\
\text { Cities }\end{array}$ & Florida & $\begin{array}{l}\text { Twin } \\
\text { cities }\end{array}$ & Florida \\
\hline Relative discontinuity & $-\mathrm{S}$ & $-\mathrm{S}$ & $-\mathrm{S}$ & $-\mathrm{S}$ & $-\mathrm{S}$ & $-\mathrm{S}$ & $-\mathrm{S}$ \\
\hline Shapefactor & $-\mathrm{S}$ & $-\mathrm{S}$ & $-\mathrm{S}$ & $-\mathrm{S}$ & $-\mathrm{S}$ & NS & $-\mathrm{S}$ \\
\hline Street density & $-\mathrm{S}$ & $-\mathrm{S}$ & $-\mathrm{S}$ & $-\mathrm{S}$ & $-\mathrm{S}$ & NS & $-\mathrm{S}$ \\
\hline $\begin{array}{l}\text { Percentage of limited- } \\
\text { access highways }\end{array}$ & $+\mathrm{S}$ & $+\mathrm{S}$ & $+\mathrm{S}$ & $+\mathrm{S}$ & $+\mathrm{S}$ & $+\mathrm{S}$ & $+\mathrm{S}$ \\
\hline Arterial treeness & $-\mathrm{S}$ & $-\mathrm{S}$ & NS & $-\mathrm{S}$ & NS & $-\mathrm{S}$ & NS \\
\hline Trip circuity & $-\mathrm{S}$ & $-\mathrm{S}$ & NS & $-\mathrm{S}$ & $-\mathrm{S}$ & $-\mathrm{S}$ & NS \\
\hline Number of observations & & 4105 & 1492 & 15274 & 3228 & 2296 & 1122 \\
\hline
\end{tabular}




\section{Discussion}

Based on survey and street network data, this empirical study identified several significant relationships between network structure and travel (trip distance, VKT). The inclusion of network structure as a factor in influencing travel differentiates this research from prior research in this field. Whereas some of the analyzed network variables have so far been used in the context of urban form, network connectivity, and microneighborhood design, the role of other, so far relatively unobserved and more complex, attributes was also determined. Further the analyses presented here quantify the impact of network measures on travel.

The stratification of the data by trip purpose and across two study areas has shown similarities in the patterns of influence but minor differences in the magnitude of influence of the independent network variables. What can be concluded is that network structure does influence individual travel, even after controlling for the effect of other independent sociodemographic variables. It is important to clarify that the analyses presented here confirm the relation rather than causality between network structure and travel. Confirming causality would require the use of temporal network and travel data, to see how changes in the street network bring about corresponding changes in travel or vice versa. One of our planned extensions to the current research is to obtain and use temporal network and travel data to understand the underlying causality.

This research supplements two independent ongoing efforts to understand the relationship between network design and travel. In the first study we investigate the relationship between network structure and household travel patterns in the Twin Cities and Florida (Parthasarathi et al, 2011b). The second study relates the network structure to transportation system performance, using data from fifty metropolitan areas across the US (Parthasarathi and Levinson, 2011).

The analyses conducted so far confirm and quantify the relationship between network structure and travel. Proposed extensions to the current analyses focus on understanding the underlying theory of how and why the design of a transportation network influences travel. It is planned to use actual routes from GPS surveys (Zhu et al, 2010) to understand the role of network design in influencing travelers' perception and its corresponding impact on actual travel. Other extensions include incorporating structural measures of transit and nomotorized networks as independent variables in the analyses, since the aspects of network structure that affect nonauto travel differ.

We expect that, with such a comprehensive analysis, a clearer pattern will evolve. Guidelines on network design can then be formulated such that they support the higher level objectives of transportation planners, developers, and policy makers. The research presented here is an additional tool to analyze the travel in a region and is not meant to replace the traditional measures of urban form and the built environment.

Acknowledgements. The authors would like to acknowledge Dr Shanjiang Zhu, University of Maryland, for providing us the actual speed data for Minneapolis-Saint Paul. The authors would also like to thank NAVTEQ for providing us with a free copy of NAVTEQ Travel Patterns data for Florida.

\section{References}

Ballou R, Rahardja H, Sakai N, 2002, "Selected country circuity factors for road travel distance estimation" Transportation Research Part A $36843-848$

Boarnet M, Crane R, 2001, "The influence of land use on travel behavior: specification and estimation strategies" Transportation Research Part A 35823 - 845

Borchert J, 1961, "The Twin Cities urbanized area: past, present, future" Geographical Review 51 $47-70$

Cervero R, Gorham R, 1995, "Commuting in transit versus automobile neighborhoods" Journal of the American Planning Association $\mathbf{6 1} 210-225$ 
Cervero R, Kockelman K, 1997, “Travel demand and the 3Ds: density, diversity, and design" Transportation Research Part D 2199 - 219

Cervero R, Radisch C, 1996, "Travel choices in pedestrian versus automobile oriented neighborhoods" Transport Policy 3(3) 127 - 141

Crane R, 2000, "The influence of urban form on travel: an interpretive review" Journal of Planning Literature 15(1) 3 - 23

Derrible S, Kennedy C, 2009, "A network analysis of subway systems in the world using updated graph theory" Transportation Research Record number 2112, 17 -25

Dill J, 2004, "Measuring network connectivity for walking and biking", in 84th Annual Meeting of the Transportation Research Board paper 04-001550, Transportation Research Board, Washington, DC

Erath A, Löchl M, Axhausen K, 2009, "Graph-theoretical analysis of the Swiss road and railway networks over time" Networks and Spatial Economics $9379-400$

Frank L, Pivo G, 1994, "Impacts of mixed use and density on utilization of three modes of travel: single-occupant vehicle, transit, and walking" Transportation Research Record number 1466, $44-52$

Garrison W L, Marble D F, 1961, "The structure of transportation networks", draft of a report submitted 31 October, 1961 to US Army Transportation Research Command, Fort Eustis, Virginia, by the Transportation Center at Northwestern University under contract DA-44-177TC-685, Transportation Geography Study, Transportation Center at Northwestern University, Evanston, IL

Haggett P, Chorley R, 1969 Network Analysis in Geography (Edward Arnold, London)

Handy S, 1992, "Regional versus local accessibility: neo-traditional development and its implications for non-work travel" Built Environment 18 253-267

Hess P, 1997, "Measures of connectivity-comparison of pedestrian environments in Seattle and Bellevue suburbs, Washington" Places (Cambridge, Mass) $1158-65$

Jiang B, Claramunt C, 2004, "Topological analysis of urban street networks" Environment and Planning B: Planning and Design $31151-162$

Kansky K, 1963 Structure of Transportation Networks: Relationships Between Network Geometry and Regional Characteristics PhD thesis, RP84, Department of Geography, University of Chicago

Kissling C, 1969, "Linkage importance in a regional highway network" The Canadian Geographer 13(2) $113-127$

Kitamura R, Mokhtarian P, Daidet L, 1997, "A micro-analysis of land use and travel in five neighborhoods in the San Francisco Bay Area" Transportation 24(2) 125-158

Kockelman K, 1997, "Travel behavior as function of accessibility, land use mixing, and land use balance: evidence from San Francisco Bay Area” Transportation Research Record number 1607, $116-125$

Krizek K, 2003, "Operationalizing neighborhood accessibility for land use - travel behavior research and regional modeling" Journal of Planning Education and Research 22 270-287

Levinson D, El-Geneidy A, 2009, "The minimum circuity frontier and the journey to work" Regional Science and Urban Economics $39732-738$

Levinson D, Harder K, Bloomfield J, Winiarczyk K, 2004, "Weighting waiting: evaluating perception of in-vehicle travel time under moving and stopped conditions" Transportation Research Record number 1898, 61 - 68

Levinson D, Harder K, Bloomfield J, Carlson K, 2006, “Waiting tolerance: ramp delay vs. freeway congestion" Transportation Research Part F: Psychology and Behaviour 91-13

Li S, Shum Y, 2001, "Impacts of the National Trunk Highway system on accessibility in China" Journal of Transport Geography 9(1) $39-48$

McNally M, Kulkarni A, 1997, "Assessment of influence of land use-transportation system on travel behavior" Transportation Research Record number 1607, $105-115$

Marshall S, 2005 Streets and Patterns (Spon, New York)

Parthasarathi P, Levinson D, 2011, "Network structure and metropolitan mobility", paper presented at 90th Annual Meeting of the Transportation Research Board, Washington, DC

Parthasarathi P, Hochmair H, Levinson D, 2011a, "Network structure and travel time perception", working paper, Nexus Research Group, University of Minnesota

Parthasarathi P, Levinson D, Hochmair H, 2011b, "Network structure and activity spaces", paper presented at 90th Annual Meeting of the Transportation Research Board, Washington, DC

Rodrigue J-P, Comtois C, Slack B, 2006 The Geography of Transport Systems (Routledge, London)

Southworth M, Ben-Joseph E, 2003 Streets and the Shaping of Towns and Cities (Island Press, Washington, DC) 
Srinivasan S, 2002, "Qualifying spatial characteristics of cities" Urban Studies 392005 - 2028

Taaffe E, Gauthier H, Morton E, 1996 Geography of Transportation (Prentice-Hall, Upper Saddle River, NJ)

van Exel N A, Rietveld P, 2010, "Perceptions of public transport travel time and their effect on choice-sets among car drivers" Journal of Transport and Land Use 2(3/4) 75 - 86

Wardrop J, 1952, "Some theoretical aspects of road traffic research" Proceedings of the Institute of Civil Engineers 1325 - 378

Xie F, Levinson D, 2007, "Measuring the structure of road networks" Geographical Analysis $39336-356$

Zhang L, Xie F, Levinson D, 2009, "Illusion of motion: variation of subjective value of travel time under different driving conditions" Transportation Research Record number 2135, 34-42

Zhu S, 2010 The Roads Taken: Theory and Evidence on Route Choice in the wake of the I-35 W Mississippi River Bridge Collapse and Reconstruction $\mathrm{PhD}$ thesis, Department of Civil Engineering, University of Minnesota, Minneapolis, MN

Zhu S, Tilahun N, Levinson D, He X, 2011, "Travel impacts and adjustment strategies of the collapse and the reopening of the I-35W Bridge", in Network Reliability in Practice Eds D M Levinson, H X Liu, M Ball (Springer, New York) pp $21-36$

Zhu S, Levinson D, Liu H, 2010, "Measuring winners and losers from the new I-35W Mississippi River Bridge", presented at the 89th Transportation Research Board Conference, Washington, DC, working paper, Nexus Research Group, University of Minnesota 
Conditions of use. This article may be downloaded from the E\&P website for personal research by members of subscribing organisations. This PDF may not be placed on any website (or other online distribution system) without permission of the publisher. 